\title{
Geopolítica da língua francesa e colonialismo
}

O caso de "L'éducation des indigènes" (1897), de Paul Vidal de la Blache

Geopolitics of French language and colonialism: The case of Paul Vidal de la Blache' "L'éducation des indigènes" (1897)

Géopolitique de la langue française et colonialisme: Le cas de «L'éducation des indigènes » (1897) par Paul Vidal de la Blache Geopolítica de la lengua francesa y colonialismo: el caso de "L'éducation des indigènes" (1897), de Paul Vidal de la Blache

\section{Guilherme Ribeiro}

\section{OpenEdition}

Journals

Edição electrónica

URL: https://journals.openedition.org/terrabrasilis/4178

DOI: 10.4000/terrabrasilis. 4178

ISSN: 2316-7793

Editora

Rede Brasileira de História da Geografia e Geografia Histórica

Refêrencia eletrónica

Guilherme Ribeiro, «Geopolítica da língua francesa e colonialismo», Terra Brasilis [Online], 11 | 2019, posto online no dia 31 agosto 2019, consultado o 05 dezembro 2022. URL: http://

journals.openedition.org/terrabrasilis/4178 ; DOI: https://doi.org/10.4000/terrabrasilis.4178

Este documento foi criado de forma automática no dia 5 dezembro 2022.

All rights reserved 


\title{
Geopolítica da língua francesa e colonialismo
}

\author{
O caso de "L'éducation des indigènes" (1897), de Paul Vidal de la Blache \\ Geopolitics of French language and colonialism: The case of Paul Vidal de la \\ Blache' "L'éducation des indigènes" (1897) \\ Géopolitique de la langue française et colonialisme: Le cas de "L'éducation des \\ indigènes » (1897) par Paul Vidal de la Blache \\ Geopolítica de la lengua francesa y colonialismo: el caso de "L'éducation des \\ indigènes" (1897), de Paul Vidal de la Blache
}

\section{Guilherme Ribeiro}

\section{NOTA DO EDITOR}

O presente comentário, elaborado pelo professor Guilherme Ribeiro, serve como apresentação ao texto de Vidal de la Blache A educação dos nativos (L'éducation des indigènes, 1897), que a Terra Brasilis oferece a seus leitores neste número, em tradução do mesmo professor Ribeiro.

\section{Um breve comentário}

1 Pensando didaticamente a circulação da ciência a partir da imagem de um simples quebra-cabeças, da caixa de Vidal de la Blache montada no Brasil ficaram de fora as peças geopolítica, fronteira, território e colonialismo. Porém, ao recuperarmos a totalidade de seu legado não é difícil perceber que aquela imagem é muito mais complexa que supomos. Além disso, o fato de que esse documento tenha passado em branco mesmo entre os que ressaltaram a inclinação de Vidal ao colonialismo e à geopolítica só reforça seu valor (Berdoulay, 1981; Nicolas-Obadia \& Guanzini, 1987; Nicolas-Obadia, 1988; Soubeyran, 1997; Mercier, 2009). 
2 Embora não tenha elaborado um conceito de alcance geopolítico como o Lebensraum de Ratzel ou uma tese geopolítica como a do heartland de Mackinder, ao abordar sua obra como uma interpretação dos principais desafios da modernidade - de um lado, o rápido progresso dos transportes, das comunicações e da engenharia e seus impactos locais e globais sobre a multissecular organização espacial rural progressivamente alterada pela industrialização e pela urbanização e, de outro, as disputas e os acordos internacionais por territórios no âmago da Era dos Impérios - nota-se que ela foi atravessada por considerações de caráter geopolítico, seja mirando as delimitações territoriais francesas na Europa durante o turbulento período entre a Guerra Franco-Prussiana e a Primeira Guerra Mundial, seja cobiçando a salvaguarda das colônias na África, na Ásia e nas Américas (Ribeiro, 2010).

3 Enquadra-se à risca nessa conjuntura $A$ educação dos nativos, síntese preciosa a definir a modernidade como experiência de deslocamento, conquista e alteridade. ${ }^{1}$ Ao projetar o mundo à sua imagem e semelhança, os Impérios Europeus o fizeram tanto graças ao seu poderio técnico-bélico quanto através da mobilização de seus intelectuais, ${ }^{2}$ cujas intervenções públicas em espaços de promoção do colonialismo como a Union Coloniale Française ou a Société de géographie commerciale de Paris - onde pronunciara anos antes discurso apologético em cerimônia de premiação a exploradores por seus feitos (até mesmo no Brasil) e cuja comissão responsável foi presidida por ele próprio (Vidal de la Blache, 1890-1891) - imantavam professores, industriais, comerciantes, políticos, missionários e exploradores em prol da superioridade da civilização, da cultura e da ciência franceses em relação aos outros, aos diferentes, aos demais povos e "raças" do mundo (ver Singaravélou, 2008). É por esta razão que críticos inovadores como Edward Said, Aníbal Quijano e Walter Mignolo atentaram para a dimensão simbólico-discursiva do imperialismo e suas sequelas político-epistemológicas, pois a criação de narrativas e imagens de alto poder persuasivo oriundas de áreas como geografia, história, antropologia, sociologia, literatura e pintura resultou nada menos que na colonização do próprio imaginário (cf. Quijano, 2010:124 [2000]; Said, 2007 [1978]; Mignolo, 2007).

4 A educação dos nativos é exemplo sintomático disto. Republicano, homem das letras e da ciência, não é mera coincidência Vidal de la Blache ter privilegiado a dominação intelectual em detrimento da força física. Diante da inferioridade numérica francesa em relação aos nativos, como gerir os territórios e suavizar as cizânias com as populações ditas d'outre-mer? Diversamente do britânico Mackinder, para quem a solução estaria na manipulação das paisagens como meio de criação de identidades entre metrópole e colônia (Mackinder, 2014 [1911]), a resposta do francês localizava-se na língua. Evidentemente, não se trata do aprendizado do árabe pelos franceses, mas da propagação do ensino do idioma de Jules Ferry (citado elogiosamente, diga-se) alcançando crianças e mulheres - sobretudo as pertencentes às classes populares, pois as elites já manifestam natural interesse por questões intelectuais e não existe verdadeira mudança sem as "massas" (Vidal de la Blache, 1897: 356). Embora tal atitude talvez possa transparecer (não sem reservas, claro) certo ar progressista - ele também se entristece ao saber que após os estudos as mulheres retornam a um cotidiano doméstico "sem livros" e "apático" (idem, p. 359) -, por trás dela existe também o estímulo e a legitimação a um projeto de geopolítica da língua francesa a ser posto em prática nas colônias como forma de suavizar o estranhamento causado pela alteridade ou, para ser mais explícito, pelas tensões oriundas da dominação metropolitana. Afinal, segundo entendia Vidal, "nossas intenções são, seguramente, excelentes, mas são mal 
interpretadas" (ibidem, p. 354). o fato de a Alliance Française ter surgido pouco antes de L'éducation des indigènes em 1883 e ter como um dos fundadores um geógrafo (Pierre Foncin [1841-1916]) traduz o espírito daqueles tempos, do casamento políticointelectual entre Geografia e Letras.

Poderosa o suficiente para facilitar o diálogo entre colonizadores e nativos, a língua francesa teria ainda a capacidade de estabelecer "laços morais" entre eles, tidos por Vidal como "o mais forte de todos" (ibid., p. 359). E declara: "Quando os sons de nosso idioma lhes forem familiares, quando este primeiro laço se formar entre eles e nós, será a hora dos nossos livros e, com estes, virão nossas ideias e, pouco a pouco, nossa influência moral" (ibid., p. 357). Aliás, o vocábulo moral e suas variações aparecem nove vezes no decorrer do artigo e expressam uma sorte de normatização ou legislação unilateral da parte dos colonizadores em relação aos colonizados. É assim que lemos expressões como "ascendência moral", "influência moral" e "conquista moral", juntamente com "moralmente estranhos", "miséria [intelectual e] moral" e "vida moral". Não é casual, portanto, seu apelo endereçado notadamente aos missionários católicos e protestantes - o que o leva, inclusive, a aludir ao papel histórico dos jesuítas na educação do Novo Mundo (ibid., p. 359).

Diferente das resenhas sobre a África veiculadas nos Annales de Géographie entre $1893 \mathrm{e}$ 1911 - Le Sahara par Schimmer (1893), Madagascar et Menuthias, d'après M. Grandidier (1894), La zone frontière de l'Algérie et du Maroc, d'après de nouveaux documents (1897), Les civilisations africaines d'après Frobenius (1899), L'Afrique Centrale Française, par A. Chevalier (1908), La conquête du Sahara d'après E. F. Gautier (1911) e Les confins algero-marrocains, d'après le livre de Augustin Bernard (1911) - nas quais Vidal pareceu sempre preocupado em vincular questões políticas às científicas, uma característica a tornar A educação dos nativos peça singular de seu puzzle é justamente o compromisso da missão civilizatória francesa para com os colonizados.

Então, pergunto se, no contato com essa multidão de povos que nos são moralmente tão estranhos [étrangers], não experimentamos algo como um calafrio, um frisson de inquietude, e se, diante dessa ignorância, não se coloca, na consciência de cada um, imperiosamente, o dever de ir ao encontro desses nativos, de abordá-los direta e francamente para tentar estabelecer entre nós e eles algumas noções comuns; para fazê-los compreender quem nós somos, o que há de saudável e de bom nessa civilização que, em geral, eles conhecem apenas pelas aparências mais fúteis; para encontrar um meio de fazê-los apreciar o que viemos fazer em seu país, país que lhes pertence e que deve, também, tornar-se o nosso. (ibid., p. 355)

7 Não é preciso muito para verificar as contradições desse posicionamento face aos ideais liberais da Revolução de 1789 e da Terceira República (1870-1940) (ver Conklin, 1997). No mesmo diapasão crítico, quando o deputado Charles Benoist reuniu um conjunto de intelectuais visando projetar a configuração ideal das fronteiras francesas e européias de acordo com os interesses franceses, um dos textos cardeais sobre o nacionalismo explorado pelo Comité d'Études era Qu'est-ce que c'est une nation, de Ernst Renan, para quem a língua francesa não assumia o centro das atenções. ${ }^{3}$ Motivo implícito: tratava-se de sobrevalorizar as afinidades da região da Alsácia-Lorena em relação à França, embora fosse um espaço majoritariamente de língua alemã. Neste caso, o apelo concentrou-se na memória, no passado comum, nos vínculos com o solo. Dentre os participantes do Comitê estavam os geógrafos Lucien Gallois, Emmanuel de Martonne e, na vice-presidência, Paul Vidal de la Blache (Heffernan, 2001). Grife-se ainda o contraste entre o matiz conciliatório e romântico dos escritos vidalianos destinados ao povo e às regiões franceses e o tom tenso e árido pairando sobre as explicações quase 
sempre litigiosas votadas aos demais impérios e às colônias. Nesta linha de raciocínio, a atmosfera calorosa e afetiva típica do conceito de gêneros de vida, essencial na conformação do elogio à diversidade francesa forjada na longa duração, foi totalmente ignorada pelas estratégias imperiais de conquista dos territórios e dos povos afroasiáticos votadas à exploração de mão-de-obra e de recursos naturais.

Graças aos esforços descoloniais, hoje temos clara consciência desse movimento: o que vale para os europeus não vale para os demais. Todavia, muito antes disso, como não se surpreender com o abismo entre as escolhas de Vidal de la Blache e as dos anarquistas Élisée Reclus (1830-1905) e Piotr Kropotkin (1842-1921)? Não se está a sugerir uma abordagem maniqueísta, pois pesquisadores e leitores de história da geografia no Brasil já atingiram maturidade suficiente para desconfiar de fórmulas tão sedutoras quanto simplificadoras. Todavia, não é raro incorrermos no equívoco de acreditar em um gênero de determinismo histórico a apregoar que a estrutura de pensamento na Europa do século XIX necessariamente condenava os geógrafos ao conservadorismo. Assim, a menção ao anarquismo ganha relevo, pois, ao desnudar uma agenda antagônica ao Estado, à escravidão e à tomada de territórios em prol da ajuda mútua, da igualdade entre os povos e de uma pedagogia emancipatória, ele nos impele a um processo de desnaturalização e desmistificação dos perfis intelectual, editorial e político formadores dos cursos de geografia universitária emergentes de políticas estatais governamentais na Alemanha, França e Inglaterra no seio da Era dos Impérios (ver Ferretti, 2013 [2012], 2013, 2018, 2018a).

Em nossos dias, ao nos confrontarmos com o desafio labiríntico de comunicação global hegemonizado pela língua inglesa e o imperativo de pluralizar esse diálogo estendendo a capacidade de penetração de outros idiomas e de formas de representar o mundo, traduzir um artigo redigido em uma língua antes imperial (porém em visível declínio) para uma outra histórica e intelectualmente influenciada por ela e cujo tema versa sobre a propaganda ideológica do francês em espaços colonizados nos conscientiza de que a dimensão reacionária infiltrada no ensino sempre traz consigo seu germe libertário.

\section{BIBLIOGRAFIA}

Berdoulay, Vincent (1995 [1981]). La formation de l'école française de géographie. Paris: Éditions du CTHS.

Conklin, Alice L (1997). A mission to civilize. The republican idea of empire in France and West Africa, 1895-1930. Stanford: Stanford University Press.

Ferretti, Federico (2018a). Revolutions and their places. The anarchist geographers and the problem of nationalities in the Age of Empire (1875-1914). In: Ferretti, Federico; de la Torre, Gerónimo Barrera; Ince, Anthony; Toro, Francisco (Eds.). Historical Geographies of Anarchism: Early Critical Geographers and Present-Day Scientific Challenges. London and New York: Routledge, pp. 113-128. 
Ferretti, Federico (2018). Evolução e revolução: os geógrafos anarquistas Elisée Reclus e Pëtr Kropotkin e sua relação com a ciência moderna, séculos XIX e XX. História, Ciências, Saúde Manguinhos, v. 25, n. 2, pp. 1-16.

Ferretti, Federico (2013). “Geografia, educação libertária e escola pública na Europa entre os séculos XIX e XX: um programa de emancipação através do saber”. Elisée, Revista de Geografia da $U E G$, n. 2, v. 2, pp. 9-24.

Ferretti, Federico. "Eles têm o direito de expulsar-nos": a Nova Geografia Universal de Élisée Reclus. Espaço e Economia, 3 (2013 [2012]). Tradução de Guilherme Ribeiro.

Heffernan, Mike (2001). "History, Geography and the French National Space: The Question of Alsace-Lorraine, 1914-18”. Space and Polity, v. 5, n. 1, pp. 27-48.

Mackinder, Halford John (2014 [1911]). “O ensino de geografia sob a ótica imperial e os usos que podem e devem ser feitos da instrução visual”. Geographia (UFF), v. 16, p. 142-152. Tradução de Guilherme Ribeiro e Leroy Honorio Azevedo.

Mercier, Guy (2009). "La géographie de Paul Vidal de la Blache face au litige guyanais: la science à l'épreuve de la justice". Annales de Géographie, n. 667, pp. 294-317.

Mignolo, Walter D (2007). La idea de América Latina: la herida colonial y la opción decolonial. Barcelona: Gedisa Editorial. Tradução de Silvia Jawerbaum y Julieta Barba

Nicolas-Obadia, Georges (1988). "Paul Vidal de la Blache et la politique". Bulletin de l'Association Géographique Française, n. 65, v. 4, pp. 333-337.

Nicolas-Obadia, Georges; Guanzini, Catherine (1987). "Géographie et Politique: Paul Vidal de la Blache". Eratosthene-Meridien, v. 1.

Quijano, Anibal (2010). Colonialidade do poder e classificação social. In: Santos, Boaventura de Sousa, Meneses, Maria Paula (Orgs.). Epistemologias do Sul. $6^{\text {ạ }}$ ed. São Paulo: Cortez.

Renan, Ernest (1997 [1882]). “Que é uma nação?”. Plural, Sociologia (USP), v. 4, 1ํsem, pp. 154-175. Tradução de Samuel Titan Jr.

Ribeiro, Guilherme (2010). “Território, Império e Nação: a Geopolítica em Paul Vidal de la Blache". Revista da Anpege, v. 6, pp. 29-42.

Said, Edward W. Orientalismo. O Oriente como invenção do Ocidente. São Paulo: Cia. das Letras (2007 [1978]). Tradução de Rosaura Eichenberg.

Singaravélou, Pierre (Dir.) (2008). L'empire des géographes. Géographie, exploration et colonisation (XIX-XX siècle). Paris: Belin.

Sloterdijk, Peter (2008 [2006]). Palácio de cristal - para uma teoria filosófica da globalização. Lisboa: Relógio d'água. Tradução de Manuel Resende

Soubeyran, Olivier (1997). Imaginaire, science et discipline. Paris: L'Harmattan.

Vidal de la Blache, Paul (1897). "L'éducation des indigènes". Revue Scientifique (Revue Rose), n. 12, tome VII, 20 mars, pp. 353-360.

Vidal de la Blache, Paul (1890-1891). "Rapport sur les médailles de 1890". Bulletin de la Société de géographie commerciale de Paris, tome XIII. 


\section{NOTAS}

1. Conforme livre inspiração advinda da filosofia geográfica do alemão Peter Sloterdijk em Palácio de cristal. Para uma teoria filosófica da globalização (Sloterdijk, 2008 [2006]).

2. Em 1897 Vidal ainda era professor da École Normale Supérieure, mas no ano seguinte já estava no Institut de Géographie na Sorbonne. De todo modo, a Revue Scientifique (Revue Rose) que acolheu L'éducation des indigènes não era um periódico colonial stricto sensu.

3. "Constitui fato honroso para a França que ela jamais tenha procurado obter a unidade linguística através de medidas coercitivas. Não é possível ter os mesmos sentimentos e pensamentos ou amar as coisas em línguas diferentes? [...] Essa atenção voltada exclusivamente à língua tem, como no caso da atenção exagerada à raça, seus perigos e inconvenientes. Quem se excede nessa direção é levado a se enclausurar, a se restringir a uma cultura supostamente nacional; enfurnando-se no conventículos de compatriotas, perde o artigo fresco que se respira no vasto campo da humanidade" (Renan, 1997: 169-170 [1882]).

\section{RESUMOS}

Proferida na Union Coloniale Française no ano de 1897, a conferência "L'éducation des indigènes" ["A educação dos nativos"] é um dos textos mais explícitos sobre a defesa do imperialismo assinados pelo geógrafo francês Paul Vidal de la Blache (1845-1918), mas nem por isso recebeu a devida atenção por parte de seus estudiosos. Ao argumentar sobre a centralidade do ensino de língua francesa entre crianças, mulheres e elites como instrumento capaz de amenizar as tensões da colonização, Vidal de la Blache oferece uma justificativa preciosa tanto para vertermos ao portugués seu texto quanto para refletirmos sobre as políticas de tradução acionadas na história da geografia no Brasil no século XX.

Delivered as a conference at the Union Coloniale Française in 1897, "L'éducation des indigènes" ["The instruction of natives"] is one of the more explicit papers relating to colonialism written by the French geographer Paul Vidal de la Blache (1845-1918), despite the fact that it is not very well known even among experts. In arguing about the French-language teaching among children, women, and elites as a helpful tool for easing the conflicts of colonization, he offers a good alibi both to translating his text and to reflect about the politics of translation put in practice by the history of Brazilian geography in the last century.

Prononcée à l'Union Coloniale Française en 1897, la conférence «L'éducation des indigènes » est un des soutiens les plus éloquentes à la cause coloniale signés par le géographe Français Paul Vidal de la Blache (1845-1918), même si cet article n'est pas très connu parmi ses experts les plus importants. Appuyé sur la centralité de l'enseignement de la langue française parmi les enfants, les femmes et les élites en tant qu'outil capable de soulager les tensions de la colonisation, Vidal de la Blache nous donne un alibi parfait pour traduire son texte et, au même temps, pour réfléchir sur les politiques de traduction menées par l'histoire de la géographie brésilienne dans le XXème siècle.

Proferida en la Union Coloniale Française en el año de 1897, la conferencia "L'éducation des indigènes" ["La educación de los nativos"] es uno de los textos más explícitos sobre la defensa del imperialismo firmados por el geógrafo francés Paul Vidal de la Blache (1845-1918), a pesar de lo 
cual no ha recibido la debida atención por parte de sus estudiosos. Al argumentar sobre la centralidad de la enseñanza de la lengua francesa a los niños, mujeres y élites como instrumento capaz de suavizar las tensiones de la colonización, Vidal de la Blache ofrece una justificación preciosa tanto para vertir al portugués su texto como para reflexionar sobre las políticas de traducción ejercidas en la historia de la geografía en Brasil en el siglo XX.

\section{ÍNDICE}

Keywords: modernity, history of Brazilian geography, politics of translation, the geopolitics of French, colonialism

Palavras-chave: modernidade, história da geografia no Brasil, políticas de tradução, geopolítica da língua francesa, colonialismo

Palabras claves: modernidad, historia de la geografía en Brasil, políticas de traducción, geopolítica de la lengua francesa, colonialismo

Mots-clés: modernité, l'histoire de la géographie brésilienne, politiques de traduction, géopolitique de la langue française, colonialisme

\section{AUTOR}

\section{GUILHERME RIBEIRO}

Laboratório Política, Epistemologia e História da Geografia, Departamento de Geografia, Programa de Pós-Graduação em Geografia, Universidade Federal Rural do Rio de Janeiro (LAPEHGE/PPGGEO/UFRRJ).

geofilos@msn.com 